\title{
Allergic reactions to hyaluronidase in pain management -A report of three cases-
}

\author{
Tae Wan Kim¹, Jae Hoon Lee ${ }^{1}$, Kyung Bong Yoon ${ }^{2}$, and Duck Mi Yoon ${ }^{2}$ \\ ${ }^{1}$ Department of Anesthesiology and Pain Medicine, CHA Bundang Medical Center, CHA University College of Medicine, Seongnam, \\ ${ }^{2}$ Department of Anesthesiology and Pain Medicine, Anesthesia and Pain Research Institute, Yonsei University College of Medicine, \\ Seoul, Korea
}

Hyaluronidase has been gaining interest because it reduces tissue edema and fibrosis. Although rare, hyaluronidase has been shown to cause allergic reactions. A few cases of allergic reactions following hyaluronidase administration have been reported. Most of the described patients presented allergic reactions after peribulbar anesthesia for eye surgery. In this report, we describe three patients who experienced with allergic reactions to hyaluronidase following pain management. Two of the patients had a history of uneventful injection with hyaluronidase. All patients were afebrile and blood tests results were normal. Intradermal skin tests were positive. These clinical findings were helpful in establishing the differential diagnosis of infection. Although allergic reaction to hyaluronidase is rare and mostly benign, this must be considered before treating patients. (Korean J Anesthesiol 2011; 60: 57-59)

Key Words: Allergic reaction, Hyaluronidase.

Hyaluronidase is an enzyme with spreading activity [1] that hydrolyzes hyaluronic acid which is a key element of connective tissue [2]. Thus, the spread of local anesthetics can be improved by hyaluronidase. Clinically, it reduces tissue swelling due to trauma and also reduces fibrosis to fibrin deposits and chronic inflammation [3]. Therefore, it has been gaining interest for use in chronic pain management.

Although hyaluronidase has been used worldwide, only a few allergic reactions to hyaluronidase have been reported. Most of the described patients showed allergic reactions after peribulbar anesthesia for eye surgery $[2,4-7]$. The authors describe three cases of allergic reactions after hyaluronidase administration in pain management.

\section{Case Reports}

\section{Case 1}

A 68-year-old woman with lower back pain due to spinal stenosis underwent caudal block with $0.2 \%$ lidocaine and $1,500 \mathrm{IU}$ of hyaluronidase (H-lase ${ }^{\circledR}$; Kuhnil, Korea). She had previously received uneventful caudal block with same mixture

Received: July 20, 2010. Revised: August 23, 2010. Accepted: September 7, 2010.

Corresponding author: Duck Mi Yoon, M.D., Ph.D., Department of Anesthesiology and Pain Medicine, Anesthesia and Pain Research Institute, Yonsei University College of Medicine, 134, Shinchon-dong, Seodaemun-gu, Seoul 120-752, Korea. Tel: 82-2-2228-2420, Fax: 82-2-312-7185, E-mail: dmyoon@yuhs.ac

(c) This is an open-access article distributed under the terms of the Creative Commons Attribution Non-Commercial License (http:// creativecommons.org/licenses/by-nc/3.0/), which permits unrestricted non-commercial use, distribution, and reproduction in any medium, provided the original work is properly cited. 
of drugs. After injection, she complained of itching sensation, and a generalized maculo-papular rash developed. However, no hypotension was found. Because she had several uneventful injections of local anesthetics, hyaluronidase was suspected. She was treated with dexamethasone and pheniramine intravenously. After one hour, symptoms diminished. Subseqeuntly, she has not shown any allergic response to drugs excluding hyaluronidase during pain management.

\section{Case 2}

A 35-year-old woman suffering from medial elbow pain was injected with $1 \%$ lidocaine and 1,500 IU of hyaluronidase into the common flexor tendon. Her previous history of exposure to hyaluronidase was unknown. Twelve hours later, the injection site was swollen along with mild pain. These symptoms continued for one day. The patient was afebrile. Besides the complete blood cell count, erythrocyte sedimentation rate and C-reactive protein level were normal. She was suspected to be allergic to hyaluronidase, and the subsequent intradermal skin allergy test result was positive. Consequently, hyaluronidase was eliminated from the injection. Since she was treated with only $1 \%$ lidocaine, there have been no allergic reactions identified.

\section{Case 3}

A 55-year-old woman with medial knee pain received an injection of $1 \%$ lidocaine and 1,500 IU of hyaluronidase into her anserinus bursa. She also had a history of uneventful injection with the same mixture of drugs several weeks beforehand. The following day, she showed a severely swollen medial knee that lasted for three days. She was not pyrexic and blood test results were normal. Skin allergy test revealed reactivity to hyaluronidase. She received several injections without hyaluronidase and, consequently, no allergic reactions were observed.

\section{Discussion}

Although hyaluronidase has been extensively used in anesthesia and pain medicine, there are very few reported cases of hypersensitivity reaction. Kempeneers et al. [4] were the first to report on the etiology of hyaluronidase reaction in five cases. Allergic reactions to hyaluronidase are rare (incidence is $1 / 2,000$ ) [2], and most of these occur in peribulbar anesthesia during ophthalmic surgery [8]. To our knowledge, however, this is the first report of allergic reaction to hyaluronidase during pain management.

The clinical manifestation of allergic reaction to hyaluronidase after peribulbar anesthesia appears to be similar in most cases [5]. Symptoms are usually mild without optic nerve compromise; however, a number of cases with reversible visual deterioration have occurred.

In general, allergic reactions to hyaluronidase result in localized responses in the injection area without generalized symptoms. However, more generalized reactions can occur according to the route of administration [8]. Szépfalusi et al. [1] reported that five of sixteen pediatric cancer patients showed immediate generalized allergic reactions after hyaluronidasechemotherapeutic agent mixture was intravenously injected. In this report, only our first patient presented with an immediate, generalized symptom after injection. As the aforementioned cases suggest, the reaction can also occur as a result of an incidental intravenous injection during caudal block. Since capillary permeability is massively increased by hyaluronidase [6], extra caution should be taken. However, further evaluation is needed to determine whether or not intravenous injection causes generalized allergic reactions.

Two patients had a history of uneventful hyaluronidase injection. Due to previous exposure, sensitization has taken place and allergic reaction to additional hyaluronidase injection was identified. On the other hand, there was a case of allergic response that appeared at the first administration of hyaluronidase [4]; thus, more than two types of allergic mechanisms may be involved. Although the exact types of hypersensitivity are unclear, many researchers have suggested that Type I and Type IV hypersensitivity are associated $[2,4,7]$. In this report, an immediate onset of symptom could represent a Type I (IgE-mediated) anaphylactic reaction. Further, reaction delayed for 24 hours could be a Type IV (T-cell- mediated) anaphylactic reaction.

The complete blood analysis, including white blood cell count, erythrocyte sedimentation rate, and C-reactive protein, could be useful to make a differential diagnosis of infection. Because all our patients had normal blood test results and they were afebrile and were systemically well, we easily ruled out infection. Skin allergy tests, such as intradermal and skin prick test, are the most specific and common methods for determining the drug responsible for Type I (IgE-mediated) anaphylactic reactions $[4,5]$. Furthermore, confirmation of delayed cell-mediated allergic reaction can be performed by lymphocytic transformation test [4]. In this report, intradermal skin test was performed with hyaluronidase (15 IU/ml) and a positive result was recorded for a persistent wheal of greater than $0.8 \mathrm{~cm}$ [9].

The addition of hyaluronidase to local anesthetics has been a controversial issue [2]. Some authors have insisted that there is insufficient evidence for using hyaluronidase with local anesthetics for chronic back pain management [10], while 
another study failed to show the advantage of hyaluronidase injection for local anesthesia [11]. When only these considerations are taken into account, due to potential allergic reactions, the use of hyaluronidase with local anesthetics in pain management might be reconsidered. However, interestingly, many other authors have insisted that hyaluronidase with local anesthetics reduces the anesthetic volume needed and improves the efficacy of local anesthesia [12-14]. Since symptoms in most cases, including this report, are benign, infrequent and not prolonged, risk of complication might not be significant. Delaere et al. [2] carefully recommended the use of hyaluronidase in spite of potential allergic responses.

In conclusion, although symptoms are usually benign and improve within a few days, an allergic reaction to hyaluronidase can occur in pain practice. Therefore, extra caution has to be urged to avoid hyaluronidase injection into patients with this allergy. Additionally, allergic reaction should be considered in the differential diagnosis of patients who demonstrate characteristic clinical symptoms and signs after hyaluronidase administration.

\section{References}

1. Szépfalusi Z, Nentwich I, Dobner M, Pillwein K, Urbanek R. IgE-mediated allergic reaction to hyaluronidase in paediatric oncological patients. Eur J Pediatr 1997; 156: 199-203.

2. Delaere L, Zeyen T, Foets B, Van Calster J, Stalmans I. Allergic reaction to hyaluronidase after retrobulbar anaesthesia: a case series and review. Int Ophthalmol 2009; 29: 521-8.

3. Geurts JW, Kallewaard JW, Richardson J, Groen GJ. Targeted methylprednisolone acetate/hyaluronidase/clonidine injection after diagnostic epiduroscopy for chronic sciatica: a prospective, 1-year follow-up study. Reg Anesth Pain Med 2002; 27: 343-52.

4. Kempeneers A, Dralands L, Ceuppens J. Hyaluronidase induced orbital pseudotumor as complication of retrobulbar anesthesia. Bull Soc Belge Ophtalmol 1992; 243: 159-66.

5. Leibovitch I, Tamblyn D, Casson R, Selva D. Allergic reaction to hyaluronidase: a rare cause of orbital inflammation after cataract surgery. Graefes Arch Clin Exp Ophthalmol 2006; 244: 944-9.

6. Minning CA Jr. Hyaluronidase allergy simulating expulsive choroidal hemorrhage. Arch Ophthalmol 1994; 112: 585-6.

7. Kirby B, Butt A, Morrison AM, Beck MH. Type I allergic reaction to hyaluronidase during ophthalmic surgery. Contact Dermatitis 2001; 44: 52 .

8. Ebo DG, Goossens S, Opsomer F, Bridts CH, Stevens WJ. Flowassisted diagnosis of anaphylaxis to hyaluronidase. Allergy 2005; 60 : 1333-4.

9. Feighery C, McCoy EP, Johnston PB, Armstrong DK. Delayed hypersensitivity to hyaluronidase (Hyalase) used during cataract surgery. Contact Dermatitis 2007; 57: 343.

10. Boswell MV, Trescot AM, Datta S, Schultz DM, Hansen HC, Abdi S, et al. Interventional techniques: evidence-based practice guidelines in the management of chronic spinal pain. Pain Physician 2007; 10: 7-111.

11. Bowman RJ, Newman DK, Richardson EC, Callear AB, Flanagan DW. Is hyaluronidase helpful for peribulbar anaesthesia? Eye (Lond) 1997; 11: 385-8.

12. Gerdesmeyer L, Rechl H, Wagenpfeil S, Ulmer M, Lampe R, Wagner K. Minimally invasive percutaneous epidural neurolysis in chronic radiculopathy. A prospective controlled pilot study to prove effectiveness. Orthopade 2003; 32: 869-76.

13. Gerdesmeyer L, Lampe R, Veihelmann A, Burgkart R, Göbel M, Gollwitzer H, et al. Chronic radiculopathy. Use of minimally invasive percutaneous epidural neurolysis according to Racz. Schmerz 2005; 19: 285-95.

14. Schulze C, Bittorf T, Walzel H, Kundt G, Bader R, Mittelmeier W. Experimental evaluation of hyaluronidase activity in combination with specific drugs applied in clinical techniques of interventional pain management and local anaesthesia. Pain Physician 2008; 11: 877-83. 